\title{
COMPARISON OF CATHETER-RELATED INFECTION RISK IN TWO DIFFERENT LONG-TERM VENOUS DEVICES IN ADULT HEMATOLOGY-ONCOLOGY PATIENTS
}

Luís Fernando Pracchia, Lúcia Cristina Santos Dias, Pedro Enrique DorlhiacLlacer and Dalton de Alencar Fisher Chamone

PRACCHIA LF et al. Comparison of catheter-related infection risk in two different long-term venous devices in adult hematology-oncology patients. Rev. Hosp. Clín. Fac. Med. S. Paulo 59(5):291-295, 2004.

PURPOSE: Infection is the leading complication of long-term central venous catheters, and its incidence may vary according to catheter type. The objective of this study was to compare the frequency and probability of infection between two types of long-term intravenous devices.

METHODS: Retrospective study in 96 onco-hematology patients with partially implanted catheters $(\mathrm{n}=55)$ or completely implanted ones $(n=42)$. Demographic data and catheter care were similar in both groups. Infection incidence and infection-free survival were used for the comparison of the two devices.

RESULTS: In a median follow-up time of 210 days, the catheter-related infection incidence was $0.2102 / 100$ catheterdays for the partially implanted devices and 0.0045/100 catheter-days for the completely implanted devices; the infection incidence rate was 46.7 (CI 95\% = 6.2 to 348.8). The 1-year first infection-free survival ratio was $45 \%$ versus $97 \%$, and the 1 -year removal due to infection-free survival ratio was $42 \%$ versus $97 \%$ for partially and totally implanted catheters, respectively $(P<.001$ for both comparisons).

CONCLUSION: In the present study, the infection risk was lower in completely implanted devices than in partially implanted ones.

KEY WORDS: Infection. Completely-inserted catheter. Partially-inserted catheter. Incidence. Lymphoma.

Since their development in the early 1970s, long-term venous catheters have been increasingly used on cancer patients, aiming at improving their quality of life and treatment. Despite having facilitated the care for such patients, these devices are not exempted from complications, and infections rank as the most common complications. ${ }^{1}$ Various reports have demonstrated that partially-implanted catheters are associated with higher infection risks compared to completelyimplanted catheters, ${ }^{2,3,4,5}$ although such correlation has not been con- firmed in some selected retrospective $^{6,7}$ and randomized ${ }^{8,9}$ studies. The majority of the published series analyzed patients with various types of neoplasias, and there is little data on the risk of infections as they relate spe-

From the Department of Hematology and Hemotherapy, Hospital das Clínicas, Faculty of Medicine, University of São Paulo and the Pró-Sangue Foundation - São Paulo/SP, Brazil.

E-mail: lupra73@uol.com.br Received for publication on October 23, 2003. cifically to catheters on patients with hematological malignancies, ${ }^{10,11,12}$ in addition to the fact that few reports have been issued by Brazilian centers. ${ }^{13,14}$

A retrospective study was thus carried out in a population of ambulatory patients with lymphomas, aiming at assessing the incidence of infectious complications related to catheters, and to determine whether the type of catheter was in any way related to the risk of infection, as well as to the risk of infection-related removal of the device. 


\section{METHODS}

All patients with lymphomas stage I to IV and implanted long-term catheters admitted to the chemotherapy unit of Pró-Sangue Foundation between January 1994 and January 2001 were included in the study. Patients with non-Hodgkin's lymphoma $(\mathrm{n}=$ 43) were treated with the CHOP protocol (cyclophosphamide $750 \mathrm{mg} / \mathrm{m}^{2}$ on day $1 \mathrm{IV}$, adriamycin $50 \mathrm{mg} / \mathrm{m}^{2}$ on day $1 \mathrm{IV}$, vincristine $2.0 \mathrm{mg}$ on day 1 $\mathrm{IV}$, and prednisone $60 \mathrm{mg} / \mathrm{m}^{2}$ on day 1 to $5 \mathrm{PO}$ ), or similar ${ }^{15}$; patients with Hodgkin's lymphoma $(n=54)$ were evenly treated with the ABVD protocol (adriamycin $25 \mathrm{mg} / \mathrm{m}^{2}$, bleomycin $10 \mathrm{mg} / \mathrm{m}^{2}$, vinblastine $6 \mathrm{mg} / \mathrm{m}^{2}$, and dacarbazine $375 \mathrm{mg} / \mathrm{m}^{2}$, all administered on day 1 and 15 of a 28-day cycle), or similar. ${ }^{16}$ In case of refractoriness or relapse, all patients were treated with ifosfamide-based ${ }^{17}$ second-line protocols. All catheters had been implanted in operating theaters by skilled surgeons in strict accordance with aseptic techniques. The brands and models of all devices varied throughout the length of the study, depending on the purchase procedures set forth by the institution. All patients were taught in-home catheter cleansing procedures: for those with partially-implanted catheters (PIC), daily cleansing of exit site and catheter extension with degerming chlorhexidine $4 \%$ during aspersion bath followed by the application of alcoholic chlorhexidine $0.5 \%$ and dressing with sterile dry gauze and tape. All patients bearing completely-implanted catheters (CIC) performed daily dressings, as explained above, until suture removal.

The catheters were used for chemotherapy administration, transfusion of hemocomponents, and collection of specimen for tests, as required. During the length of the study, catheters were manipulated solely by trained nurses, according to standardized aseptic techniques. All ambulatory dressings were performed with alcoholic chlorhexidine $0.5 \%$, sterile dry gauze, and tape. The permeability of the catheters was maintained by means of the weekly application of $2.5 \mathrm{~mL}$ of heparin solution at $100 \mathrm{U} / \mathrm{mL}$ to all lumens of PICs and $4.0 \mathrm{~mL}$ once a month to the CIC. When bacteremia was suspected, peripheral and via-catheter hemocultures were collected whenever there was blood reflux in the devices. The decision for the removal of devices was made by the attending physician, the proximal portion (tip) of all removed being sent to quantitative culture.

All patients' charts and microbiological exams were reviewed for identification of infection episodes. Catheter-related infections were defined as follows:

Bacteremia - presence of signs and symptoms of bacteremia (fever, chills, shivers, whether or not with hypoxia or hypotension) that began within 6 hours of catheter manipulation, in the absence of any other evident infectious cause, associated with positive peripheral hemoculture and positive hemoculture via catheter, or positive peripheral hemoculture and positive quantitative culture of catheter's tip, with more than 15 CFUs (colony forming units) in which the same microbiological agents were isolated, having equal sensitivity patterns to the antimicrobials.

Localized infection - inflammation, edema, erythema, and pain in the subcutaneous tunnel.

Infection rates were calculated based on their incidence per 100 catheter-days, and the comparison of the rates was performed by comparing the incidence of PIC/CIC infection, with a $95 \%$ confidence interval. The rate of infection-related removal was determined from the following ratio: number of catheters removed due to infection / total number of catheters.
The removal-due-to-infection survival time (number of days from the date of the first ambulatory evaluation to the removal of catheter due to infection), and the first-catheter-infection survival time (number of days from the date of the first ambulatory evaluation to the onset of the first infection) were also calculated using the KaplanMeier ${ }^{18}$ method. All patients without infection or removal due to infection in the whole follow-up period were censored and the date of their last evaluation was used in the survival analysis. The comparison of survival curves and infection probability in 1 year were performed with the log-rank test. To compare age medians, the nonparametric Mann-Whitney test was used; to compare percentages, the Fisher exact test was used. All tests were 2 -tailed, with a $5 \%$ significance level.

\section{RESULTS}

Out of the 96 patients analyzed, 54 (56\%) had partially-implanted catheters (PIC), and 42 (44\%) had completely implanted catheters (CIC). Both groups had comparable demographic characteristics, as demonstrated in Table 1.

One patient had more than $1 \mathrm{im}$ planted catheter, totaling 97 catheters for analysis. In a median follow-up period of 210 days (range: 3 to 1,436 days), the incidence of infections in patients with PICs was $0.2102 / 100$ catheter-days, and 0.0045/100 catheter-days in patients with CICs. The infection-incidence rate among patients with PICs and patients with CICs was 46.7 (CI 95\% = 6.2 to 348.8).

The median first infection-free survival time was 298 days for patients with PICs, and was not reached for patients with CICs $(P<.001)$. The ratio of first infection-free survival in 1 year was $45 \%$ for patients with PICs and 
97\% for patients with CICs $(P<.001)$.

The first infection-free survival curves for both groups are represented in Figure 1 .

The median removal due to infection-free survival time was 298 days for patients with PICs, and was not reached for patients with CICs $(P$ $<.001)$. The ratio of removal due to infection-free survival time in 1 year was $42 \%$ for patients with PICs, and $97 \%$ for patients with CICs $(P<.001-$ Figure 2).

The rate of infection-related device removal was higher among patients with PICs. Out of the 55 catheters in patients with PICs, 20 (36.4\%) were removed due to infection; while out of the 42 catheters on patients with CICs, only $1(2.4 \%)$ was removed due to infection $(P<.001)$. The comparison of infection-related device removals for both groups is shown on Table 2 .

\section{DISCUSSION}

In the present study, partially-implanted catheters were associated with a higher frequency of infection in a population of patients with similar diagnoses and undergoing similar treatments. The incidence of infection in this type of device was $0.2102 / 100$ catheter-days, while, for completelyimplanted catheters, it was 0.0045/100 catheter-days. This tendency to a lower infection rate in completely-implanted catheters has also been described in international series, in which the infection rate varied from 0.1 to $1.9 / 100$ catheter-days in partially-implanted devices, and from 0 to $0.18 / 100$ catheter-days in completely-implanted devices. $^{2-9}$ Two issues stand out in the evaluation of these results. First, the infection incidence rates cannot be directly compared across the different studies due to the great variability in the definition of catheter-related infection in each of them. Second, the defi-
Table 1 - Demographic data.

\begin{tabular}{lccc}
\hline & $\begin{array}{c}\text { PIC Patients } \\
\mathrm{n}=54\end{array}$ & $\begin{array}{c}\text { CIC Patients } \\
\mathrm{n}=42\end{array}$ & \\
\hline $\begin{array}{l}\text { Age }- \text { years } \\
\text { median (range) }\end{array}$ & $37(14-67)$ & $30(13-67)$ & $P=.43^{1}$ \\
$\begin{array}{l}\text { Male Sex } \\
\mathrm{n}(\%)\end{array}$ & $35(63.6)$ & $22(52.4)$ & $P=.32^{2}$ \\
\hline
\end{tabular}

PIC - partially implanted catheter, CIC - totally implanted catheter, 1 - Mann-Whitney test, 2 - Fisher exact test.

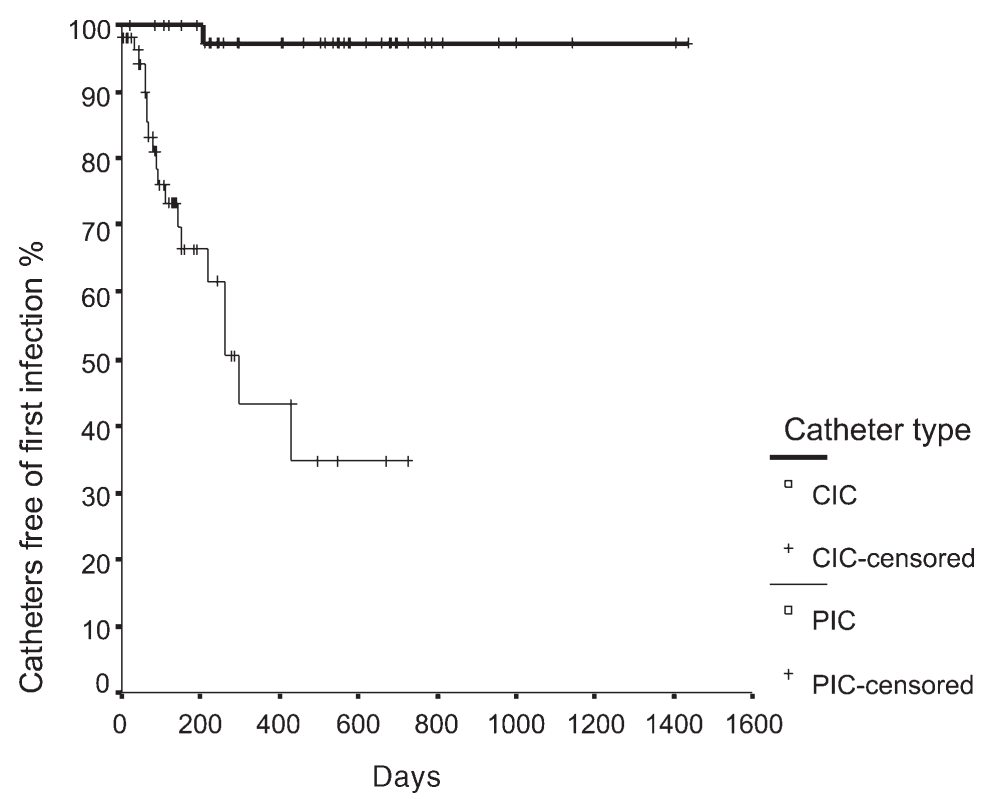

Figure 1 - Comparison of first infection-free survival curves. Survival curve indicates percentage of catheters that remain infection free over time. PIC - partially implanted catheter, CIC totally implanted catheter.

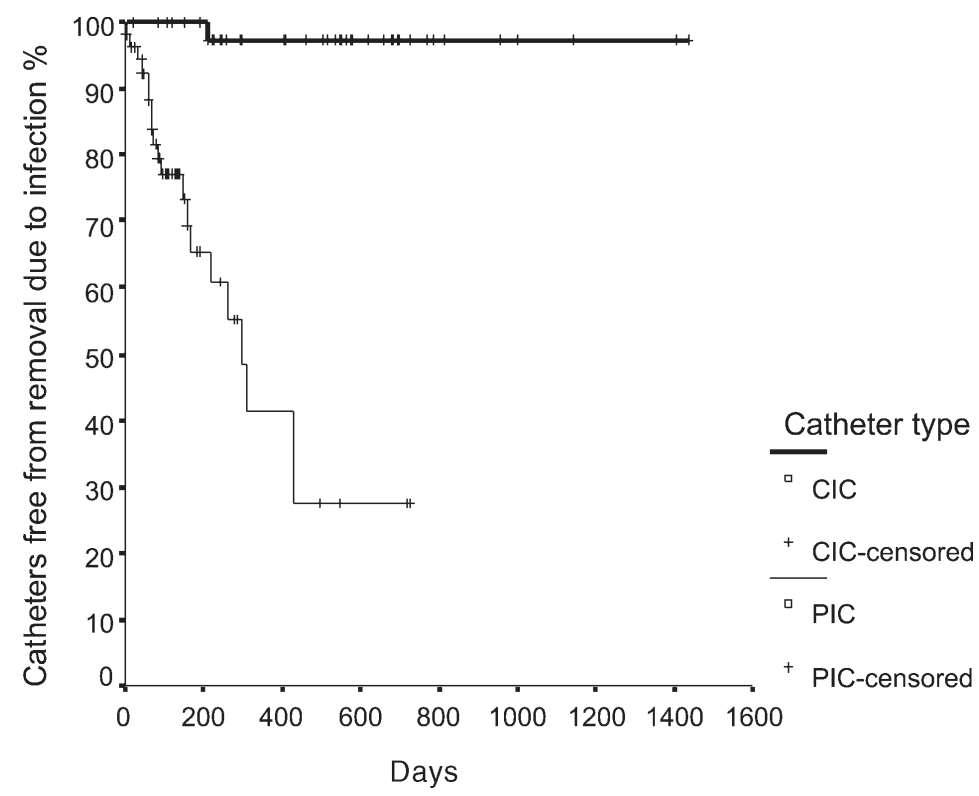

Figure 2 - Comparison of removal due to infection-free survival curves. Survival curve indicates percentage of catheters that were not removed due to infection over time. PIC partially implanted catheter, CIC - totally implanted catheter. 
Table 2 - Rate of infection-related catheter removal.

\begin{tabular}{lccc}
\hline & $\begin{array}{c}\text { PIC Patients } \\
\mathrm{n}=55^{1}\end{array}$ & $\begin{array}{c}\text { CIC Patients } \\
\mathrm{n}=42\end{array}$ & \\
\hline $\begin{array}{l}\text { Removed due infection } \\
\mathrm{n}(\%)\end{array}$ & $20(36.4)$ & $1(2.4)$ & $P<.001^{2}$ \\
$\begin{array}{l}\text { Not removed due infection } \\
\mathrm{n}(\%)\end{array}$ & & \\
\hline
\end{tabular}

PIC - partially implanted catheter, CIC - totally implanted catheter, 1 - one patient had 2 implanted catheters, 2 - Fisher exact test.

nition of catheter-related bacteremia used in the present study was very restrictive in an attempt to identify with maximum certainty only those infections that were related to catheters. This restrictive criterion may have contributed to an underestimation of the infection incidence, yet it does not render invalid the comparison of rates between the two different devices.

We also observed that the first infection-free survival time was remarkably different between types of catheters. PICs presented higher risk for infection, which was continuous during the whole period of use, while CICs presented lower risk for infection, and none was observed after the 200th day of use. It is known that the colonization of the catheter hub is one of the main sources for endoluminal contamination and infection in long-term devices. ${ }^{1}$ Therefore, it is possible that the con- tinuous exposure of non-implanted parts of the PIC to the environment may favor their colonization, thus becoming responsible for the higher risk for infection of such devices.

The duration and intensity of neutropenia episodes, also known as other important risk factors for catheter-related infection, ${ }^{6}$ were not analyzed in this study. However, since all patients in this series had the same type of neoplasia, and all underwent similar treatments, it is unlikely that there are great differences in the frequency of neutropenia across patients with either type of catheter. Thus, it is unlikely that differences in duration and intensity of episodes of neutropenia accounted for the higher incidence of infection observed in patients with PICs.

The possible causes for the higher infection risk in partially-implanted catheters are not fully known. Other risk factors for catheter infection, such as hub colonization rates ${ }^{19}$, type of cancer ${ }^{20}$, administration of parenteral nutrition ${ }^{21}$, frequency of device use ${ }^{22}$, model of catheter hub, ${ }^{23,24}$ in addition to the factors related to the in-home methods deployed by patients to care for catheters, have not been well studied, but they may change the infection incidence with catheters. Certainly, the interaction of all these factors, some of which are difficult to control even in prospective clinical studies, may explain the diverging results found by other authors. ${ }^{6-9}$

We conclude that in our series of onco-hematology patients, the partially-implanted catheters were related to a higher incidence of infection; higher infection probability within 1 year of catheter implantation, and a lower permanence length due to a higher probability of infection-related device removal. It is important to remark that, given the retrospective design of the present study and the existence of multiple risk factors for catheter infection, unrecognized biases may have influenced the results. It is of fundamental importance that particular aspects of different countries, hospitals, and patient populations be taken into account for the choice of the catheter to be used.

\section{RESUMO}

PRACCHIA LF e col. Comparação do risco de infecção relacionada a cateteres entre dois tipos de dispositivos de longa permanência em pacientes onco-hematológicos.

Rev. Hosp. Clín. Fac. Med. S. Paulo 59(5):291-295, 2004.

OBJETIVO: Infecção é a principal complicação relacionada ao uso de cateteres venosos de longa permanência em pacientes oncológicos e sua in- cidência pode variar a depender do tipo de cateter utilizado. O objetivo deste estudo foi comparar a freqüência e risco de infecção entre dois tipos de dispositivos de longa permanência.

MÉTODOS: Estudo retrospectivo com 96 pacientes onco-hematológicos portadores de cateteres parcialmente implantáveis $(n=55)$ ou totalmente implantáveis $(\mathrm{n}=42)$. Dados demográficos e cuidados com o dispositivo foram similares entre os dois grupos.
A comparação entre os dispositivos foi realizada através da avaliação da incidência de infecção e da sobrevida livre de infecção.

RESULTADOS: Em uma mediana de acompanhamento de 210 dias, a incidência de infecção relacionada ao cateter foi de 0,2102/100 cateter-dias para os dispositivos parcialmente implantáveis e de 0,0045/100 cateterdias para os totalmente implantáveis, com uma razão de incidência de 46,7 
(IC $95 \%=6,2$ a 348,8). A taxa de sobrevida livre de primeira infecção em um ano foi de $45 \%$ versus $97 \%$ e a taxa de sobrevida livre de retirada por infecção foi de $42 \%$ versus $97 \%$, respectivamente para cateter parcialmen- te ou totalmente implantável ( $p<0,001$ para ambas comparações). Conclusão: No presente estudo, o risco de infecção foi menor nos dispositivos totalmente implantáveis do que nos parcialmente implantáveis.
UNITERMOS: Infecção. Incidência. Cateter totalmente implantável. Cateter parcialmente implantável. Linfoma.

\section{REFERENCES}

1. Greene JN. Catheter-related complications of cancer therapy. Infect Dis Clin North Am 1996;10:255-95.

2. Ross MN, Haase GM, Poole MA, Burrington JD, Odom LF. Comparison of totally implanted reservoirs with external catheters as venous access devices in pediatric oncologic patients. Surg Gynecol Obstet 1988; 167:141-4.

3. Mirro J Jr, Rao BN, Kumar M, Rafferty M, Hancock M, Austin $\mathrm{BA}$, et al. A comparison of placement techniques and complications of externalized catheters and implantable port use in children with cancer. J Pediatr Surg 1990; 25:120-4.

4. Pegues D, Axelrod P, McClarren C, Eisenberg BL, Hoffman JP, Ottery FD, et al. Comparison of infections in Hickman and implanted port catheters in adult solid tumor patients. J Surg Oncol 1992; 49:156-62.

5. Mirro J Jr, Rao BN, Stokes DC, Austin BA, Kumar M, Dahl GV, et al. A prospective study of Hickman/Broviac catheters and implantable ports in pediatric oncology patients. J Clin Oncol $1989 ; 7: 214-22$.

6. Wurzel CL, Halom K, Feldman JG, Rubin LG. Infection rates of Broviac-Hickman catheters and implantable venous devices. AJDC 1988; 142:536-40.

7. Wacker P, Bugmann P, Halperin DS, Babel JF, Le Coultre C, Wyss M. Comparison of totally implanted and external catheters in paediatric oncology patients. Eur J Cancer 1992;28:841-4.

8. Mueller BU, Skelton J, Callender DP, Marshall D, Gress J, Longo $\mathrm{D}$, et al. A prospective randomized trial comparing the infectious and noninfectious complications of an externalized catheter versus a subcutaneously implanted device in cancer patients. J Clin Oncol 1992;10:1943-8.

9. Kappers-Klunne MC, Degener JE, Stijnen T, Abels J. Complications from long-term indwelling central venous catheters in hematologic patients with special reference to infection. Cancer 1989;64:1747-52.

10. Ingram J, Weitzman S, Greenberg ML, Parkin P, Filler R. Complications of indwelling venous access lines in the pediatric hematology patient: a prospective comparison of external venous catheters and subcutaneous ports. Am J Pediatr Hematol Oncol 1991;13:130-6

11. Reilly JJ JR, Steed DL, Ritter PS. Indwelling venous access catheters in patients with acute leukemia. Cancer 1984;53:219-3.

12. Severien C, Nelson JD. Frequency of infections associated with implanted systems vs. cuffed, tunneled Silastic venous catheters in patients with acute leukemia. Am J Dis Child 1991;145:1433-8.
13. Brandão MA, Rodrigues Z, Sampaio S, et al. Cateter venoso totalmente implantável em 278 pacientes oncológicos. Rev Bras Cancerol 2000; 46:49-56.

14. Moreira RCR, Batista JC, Abrão E. Complicações dos cateteres venosos centrais de longa permanência: análise de 500 implantes consecutivos. Rev Col Bras Cir 1998; 25:403-8.

15. Fisher RI, Gaynor ER, Dahlberg S, Oken MM, Grogan TM, Mize EM, et al. Comparison of a standard regimen (CHOP) with three intensive chemotherapy regimens for advanced nonHodgkin's lymphoma. N Engl J Med 1993;328:1002-6.

16. Canellos GP, Anderson JR, Propert KJ, Nissen N, Cooper MR, Henderson ES, et al. Chemotherapy of advanced Hodgkin's disease with MOPP, ABVD, or MOPP alternating with ABVD. N Engl J Med 1992;327:1478-84.

17. Cabanillas F, Hagemeister FB, Bodey GP, Freireich EJ. IMVP-16: an effective regimen for patients with lymphoma who have relapsed after initial combination chemotherapy. Blood 1982;60:693-7.

18. Kaplan EL, Meier P. Nonparametric estimation from incomplete observations. J Am Stat Assoc 1958;53:27-37.

19. Sitges-Serra A, Puig P, Linares J, Perez JL, Farrero N, Jaurrieta E, et al. Hub colonization as the initial step in an outbreak of catheterrelated sepsis due to coagulase negative staphylococci during parenteral nutrition. J Parenter Enteral Nutr 1984;8:668-72.

20. Groeger JS, Lucas AB, Coit D, LaQuaglia M, Brown AE, Turnbull A, et al. A prospective, randomized evaluation of the effect of silver impregnated subcutaneous cuffs for preventing tunneled chronic venous access catheter infections in cancer patients. Ann Surg 1993;218:206-11.

21. Llop J, Badia MB, Comas D, Tubau M, Jodar R. Colonization and bacteremia risk factors in parenteral nutrition catheterization. Clin Nutr 2001;20:527-34.

22. Groeger JS, Lucas AB, Thaler HT, Friedlander-Klar H, Brown $\mathrm{AE}, \mathrm{Kiehn} \mathrm{TE}$, et al. Infectious morbidity associated with long-term use of venous access devices in patients with cancer. Ann Intern Med 1993;119:1168-73.

23. Bouza E, Munoz P, Lopez-Rodriguez J, Jesus Perez M, Rincon C, Martin Rabadan P, et al. A needleless closed system device (CLAVE) protects from intravascular catheter tip and hub colonization: a prospective randomized study. J Hosp Infect 2003;54:279-87.

24. Leon C, Alvarez-Lerma F, Ruiz-Santana S, Gonzalez V, de la Torre MV, Sierra R, et al. Antiseptic chamber-containing hub reduces central venous catheter-related infection: a prospective, randomized study. Crit Care Med 2003;31:1318-24. 